\title{
Authors' reply to Kremer and Van de Perre
}

\author{
Nicholas J Beeching senior lecturer (honorary consultant) ${ }^{1}$, Manuel Fenech specialist trainee in \\ infectious diseases ${ }^{2}$, Catherine $\mathrm{F}$ Houlihan clinical research fellow ${ }^{3}$
}

${ }^{1}$ Liverpool School of Tropical Medicine, Liverpool L3 5QA, UK; ${ }^{2}$ Royal Liverpool University Hospital, Liverpool, UK; ${ }^{3}$ London School of Hygiene and Tropical Medicine, London, UK

Kremer and Van de Perre highlight important concerns. ${ }^{12}$ HIV incidence was increased mainly in men in the long term follow-up (3.5 years after vaccination) of the Phambili HIV vaccine trial, which used an adenovirus type 5 vectored DNA vaccine. $^{3}$ The candidate Ebola adenovirus vectored vaccine is of a different adenovirus subtype (type 3$).{ }^{4}$ However, the postulated mechanism of increased HIV risk-an increase in adenovirus type specific T cells, targets for HIV that could migrate to the gut and genitalia-may still apply.

HIV-1 prevalence in young adults in the three west African countries worst affected by Ebola is estimated at $1.1 \%$ (Liberia), $1.6 \%$ (Sierra Leone), and $1.7 \%$ (Guinea), much lower than in South Africa (19.1\%), where the Phambili trial was conducted (www.unaids.org/en/dataanalysis/datatools/aidsinfo). Ebola vaccine trials, including those using adenovirus vectors, should not be delayed. However, long term follow-up of study participants, including voluntary HIV counselling and testing, should be planned. Study participants should be made aware of the potential risk. ${ }^{3}$

Concern has been expressed about the effect of the Ebola outbreak on delivery of routine healthcare to people with HIV in affected countries. ${ }^{6}$ Parallels have been drawn between the stigma experienced by people living with HIV, survivors of Ebola, and healthcare workers looking after people with either infection. ${ }^{6}$ Yet there are no current data on the clinical presentation or prognosis of Ebola in people infected with HIV , including those taking antiretrovirals. It has been suggested that protease inhibitors and perhaps lamivudine have a protective effect. ${ }^{78}$ Survivors infected with HIV might also maintain Ebola virus in sanctuary sites, such as semen, for longer than currently described. ${ }^{9}$ Information is needed on dual infection with HIV and Ebola, and interventional studies and reports on outcomes from Ebola treatment centres in west Africa should consider this potential confounder.

Competing interests: None declared.

1 Kremer EJ, Van de Perre P. Ebola vaccines based on adenovirus vectors and risk of HIV. BMJ 2015;350:h1307.

2 Beeching NJ, Fenech M, Houlihan CF. Ebola virus disease. BMJ 2014;349:g7348. (10 December.)

3 Gray GE, Moodie Z, Metch B, et al. Recombinant adenovirus type 5 HIV gag/pol/nef vaccine in South Africa: unblinded, long-term follow-up of the phase $2 b$ HVTN 503/Phambili study. Lancet Infect Dis 2014;14:388-96.

4 Ledgerwood JE, DeZure AD, Stanley DA, et al. Chimpanzee adenovirus vector Ebola vaccine-preliminary report. N Engl J Med 2014; published online 26 Nov.

5 Rampling T, Ewer K, Bowyer G, et al. A monovalent chimpanzee Adenovirus Ebola vaccine - preliminary report. N Engl J Med 2015; published online 28 Jan.

6 Wainberg MA, Lever AM. How will the Ebola crisis impact the HIV epidemic? Retrovirology 2014;11:110.

7 Zhou $\mathrm{Y}$, Vedantham $\mathrm{P}$, Lu K, et al. Protease inhibitors targeting coronavirus and filovirus entry. Antiviral Res 2015;116C:76-84

8 Hensley LE, Dyall J, Olinger Jr GG, et al. Lack of effect of lamivudine on Ebola virus replication. Emerg Infect Dis 2015;21:550-2.

9 Rogstad KE, Tunbridge A. Ebola virus as a sexually transmitted infection. Curr Opin Infect Dis 2015;28:83-5.

Cite this as: BMJ 2015;350:h1308

๑) BMJ Publishing Group Ltd 2015 